of light, because the same treatment applied in a normal atmosphere does not produce any differences in eye colour. Thus the effect must be due to the differential depression of cellular respiration in the tissues of the two respective eyes. In this connexion it is of great interest to note that the pigment of the Drosophila eye has been shown to act as a reversible redox-system, being colourless when reduced, and fully coloured when shaken with oxygen (cf. Schultz ${ }^{3}$.

The importance of the method for embryological experimentation seems to be that deficiencies are produced by a well analysed physiological treatment, instead of by the more crude method of killing or extirpating certain parts.

Lately the method has been modified. Instead of using one single beam, the whole dish, filled with carbon monoxide, was illuminated, and several pupæ were put in at once, but the pupal cases were first varnished at various places with a quick drying, thick black varnish, as used in blinding experiments on insects.

It is proposed to extend the studies to the histology of the treated pupæ, and also to earlier developmental stages (eggs), where they may give a welcome completion of the experiments of Geigy ${ }^{4}$ with local ultra-violet treatment.

Biological Research Institute,

Alexander A. Wolsky. Tihany, Lake Balaton, Hungary. April 21.

1 Wolsky, A., J. Exp. Biol. (in the press).

${ }^{2}$ Runnström, J., Protoplasma, 10, 106 (1930).

Schultz, J., Verhandl. internat. 6. Kongr. Vererbwiss., 2, 178 (1932).

- Geigy, R., Roux's Archiv., 125, 406 (1931).

\section{Genes for Dwarfing in Rice}

THE typical dwarf varieties of rice vary in height from $10 \mathrm{~cm}$. to $75 \mathrm{~cm}$. They are characterized by shortened internodes, short and broad leaves and small compact panicles. Crosses of dwarf with normal varieties have generally shown that they are mono-recessive (Parnelli, Akemine ${ }^{2}$, Nagai $^{3}$ and Yamaguti $\left.^{4}\right)$. Sugimoto ${ }^{5}$, however, reports a dominant dwarf. Except for Akemine's work ${ }^{2}$, there have been no attempts to determine the number of genes for dwarfing in rice. He crossed two dwarfs, differing in height, and obtained tall $F_{1}$ plants. In $F_{2}$ the segregation was 9 tall; 3 first type of dwarf; 3 second type of dwarf; 1 third type of dwarf; the last phenotype being the result of segregation.

Through the courtesy of rice workers in India, Japan, Australia and the United States of America, I obtained a number of dwarf varieties. These were erossed in various combinations with the view of determining the number of genes causing dwarfness. The studies have revealed that five genes are responsible in causing short stature. The various varieties are grouped below according to the existence of genes:

\begin{tabular}{cl} 
Gene. & \multicolumn{1}{c}{ Varieties. } \\
$d_{1}$ & Japan-I \\
$d_{3}$ & Japan-II, Ratanghose, \\
& Kr-226, T-433, Mohmyaw, \\
& "Louisiana" and "California" \\
$d_{3}$ & Kolamba-dwarf \\
$d_{4}$ & $Y$-2139 \\
$d_{5}$ & Bunketu-to
\end{tabular}

It will be seen that the gene $d_{2}$ occurs very extensively. The reactions of the various gene combinations are very varied.

The full results will be reported elsewhere. B. S. KADAM.

Karjat, Bombay Presidency, April 17.

1 Parnell et al., Mem. Dept. Agr. India, Bot. Ser., 11, 185-208 (1922).

2 Akemine, Rept. Jap. Assoc. Adv. Sci., 1, 308-314 (1925).

3 Nagai, Jap. J. Bot., 8, 55-66 (1926).

Y Yamaguti, Ber. Ohara Inst., 5, 1-56 (1931).

${ }^{5}$ Sugimoto, Jap. J. Genetics, 2, 71-75 (1923).

6 Kadam, NAT URE, 129, 616-617 (1932).

\section{Growth of Lemna minor.}

$I_{N}$ view of the recent work on the growth and metabolism of Lemnia minor ${ }^{1}$, the following observations are of interest.

The multiplication of fronds in a colony of Lemna under favourable conditions has been regarded as exponential. While this conveniently expresses the growth of a colony, it does not express the rate of appearance of the daughter fronds from the individual 'mother'.

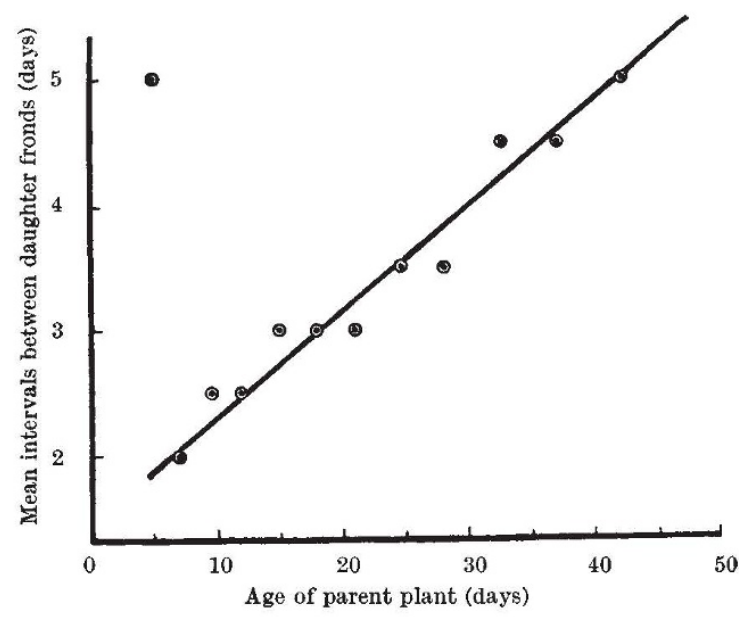

Fig. 1.

Under standard controlled conditions (full nutrient medium, illumination of 400 foot candles, temperature $25^{\circ}$ C.) a frond produces 10-12 daughter fronds in succession. These appear alternately on two sides of the mother frond. The whole process takes 40-42 days; at the end of this time the mother frond dies. The mean interval between the appearance of successive daughter fronds is not constant.

The relation between rate of production of fronds and the age of the mother frond is illustrated by the accompanying graph (Fig. 1), on which the mean intervals between daughters are entered. Apart from the five-day period before the appearance of the first daughter frond, the observations lie on a straight line. The rate of frond production is therefore a hyperbolic function of time, and for the particular environment described above may be expressed by the equation :

$$
r=\frac{1}{0 \cdot 089 t-1 \cdot 26}
$$

where $r$ is the rate, and $t$ is time in days. 